\title{
Assessment of Genetic Diversity and Variability of Maize (Zea mays L.) Inbreds
}

\author{
Varsha Gayatonde*, J.P. Shahi, K. Srivastava and Prudhvi Raj Vennela \\ Department of Genetics and Plant Breeding, Institute of Agricultural Sciences, BHU, \\ Varanasi-221005 U.P., India \\ *Corresponding author
}

\begin{tabular}{|l|}
\hline Ke y w o r d s \\
$\begin{array}{l}\text { Breeding, Diversity, } \\
\text { Inbreds, } \\
\text { Recombinants, } \\
\text { Variability }\end{array}$ \\
\hline Article Info \\
\hline $\begin{array}{l}\text { Accepted: } \\
10 \text { July } 2018 \\
\text { Available Online: } \\
10 \text { August } 2018\end{array}$ \\
\hline
\end{tabular}

\section{A B S T R A C T}

Genetic Diversity (GD) present in the germplasm is pre-requisite for crop improvement as it helps in the development of superior recombinants. Knowledge about Genetic diversity between the genotype can be utilized for the selection of diverse parents in hybridization to exploit the heterosis. Mahalanobis $\mathrm{D}^{2}$ statistics assist in grouping the genotypes into different clusters. A set of trial consisting of 20 inbred lines of maize were grown in the experimental field of IASc. BHU, Varanasi and morphological diversity and genetic variability was assessed. Based on the morphological data a cluster diagram (Through Ward's similarity coefficient) minimum distance was obtained consisting of a total of two clusters. The diversity analysis through rooted dendrogram revealed the maximum inbreds in cluster 2 and HUZM 152 found to be most diverse among the twenty experimental inbreds. Maximum intra cluster distance obtained in cluster 4 (Eucladian distance) whereas, maximum inter cluster distance found between cluster 2 and 3. Genetic variability studies indicated narrow difference in PCV and GCV for most of the traits. High heritability followed by high genetic advance under selection was found for the traits i.e., plant height and ear height. The inbreds chosen in the present study can be subjected to molecular analysis to confirm the morphological results and can be utilized in obtaining better recombinants.

\section{Introduction}

The success of plant breeding program depends on the development of high yielding, input responsive, better quality, disease and insect resistant varieties, which in turn depends on the selection of suitable plants to be utilized in crop improvement. Mahalanobis $\mathrm{D}^{2}$ statistics assist in grouping the genotypes into different clusters based on their divergence level. This analysis takes into account the contribution of each character towards the total divergence. So that provides the idea about the total genetic divergence among the genotypes with the estimates of Inter-cluster and Intra-cluster distance. Hybridization program involving genetically diverse parents belonging to different clusters would provide an opportunity for bringing together gene constellations of diverse nature, promising hybrid derivatives resulted probably due to the complementary interaction of divergent genes in parents (Ovung et al., 2012), hence, helps to pick up appropriate 
genotypes for utilization in the hybridization program.

Maize (Zea mays L.) is the world's third most important cereal after wheat and rice and popularly known as "Queen of Cereals". It has worldwide significance as human food, animal feed and for a large number of many other industrial products like glucose, starch, oil etc. It is a major food crop and main source of dietary energy and protein for the most food insecure people in the world. Maize was domesticated in Mexico, from where it was introduced to other regions of the world with diverse agro-climatic conditions (Anjali Kumari et al., 2018). Therefore, a wide diversity is found within and among the maize genotypes at both phenotypic and genotypic level. The knowledge of genetic diversity in maize is important for understanding of the genetic structure and subsequently helps the breeder in choosing desirable parents to conduct breeding program (AlBadeiry et al., 2014). The more diverse genotypes can be used to produce superior hybrids/lines, segregating population with high variability and introgression of desirable traits/genes. Therefore, there is a need to evaluate the available genotypes for the extent of genetic diversity.

\section{Materials and Methods}

Exploitation of natural genetic variability help to meet short-term objective as very often breeders are forced to meet immediate requirement of the farmers, consumers and end-users (Gayatonde et al., 2017). The present investigation was conducted during the kharif season 2015-2016 at the Agricultural Research Farm, Institute of Agricultural Sciences, Banaras Hindu University, Varanasi using twenty maize inbreds viz., HKI- 193-1, HKI 1105, CML 161, LM 10, CML 163, PBNI 3-1, HUZM 343, HUZM 152, HUZM 242, HKI 536,
HUZM 185, HKI 323, HUZM 56, HUZM 265, HKI 162, HUZM329, HKI586, HUZM 379, HUZM 53 and HUZM 246. The experiment was laid out in randomized block design (RBD) with three replications and crop was maintained as per the standard agronomic practices. The field observations were recorded for 18 traits which includes days to tasseling (DT), days to silking (DS), anthesis silking interval (ASI), Plant height (PH), ear height (EH), leaf area (LA), panicle length (PL) cob length (CL), cob diameter (CD), rows per cob (ROW), days to maturity (DM), test weight(TW), Per cent germination (PG)total soluble sugar (TSS), Per cent grain moisture (GM) grain yield per plant (GP), number of cobs per plot (NP) and yield per plot (YP). Genetic divergence analysis carried out as per Mahalanobis' $\mathrm{D}^{2}$-statistics procedure.

The $\mathrm{D}^{2}$-values between the genotypes were obtained as the sum of squares of differences of the values of the corresponding transformed variables. After arranging the $\mathrm{D}^{2}$-values of all combinations of one genotype with the others in ascending order of magnitudes, the genotypes were grouped into a number of clusters by Tocher's method described by Rao (1952). In all the combinations of genotypes, each character was ranked on the basis of $d i=$ $Y_{i}^{j}-Y_{i}^{k}$ values. Rank 1 was given to the highest mean difference and rank $p$ to the lowest mean difference, where, $p$ represented the total number of characters. The analysis of variance was done as suggested by Panse and Sukhatme (1967). Genotypic coefficient of variation (GCV), phenotypic coefficient of variation $(\mathrm{PCV})$ and heritability were estimated by formula suggested by Burton (1952). Genetic advance (GA) was calculated by the method suggested by Johnson et al., (1955).Analysis of variance for all the characters was carried out by Windows stat and the genetic parameters such as PCV and GCV, heritability broad sense $\left(h^{2}\right)$ were 
calculated (Nechifor et al., 2011), genetic advance in percent of mean (genetic gain) and expected mean in next generation were work out.

\section{Results and Discussion}

The Diversity analysis (Eucladian distance) resulted in major four clusters out of which highest intra-cluster distance can be revealed from cluster 4 (i.e. 446.66) and minimum in cluster 1 (180). Maximum intercluster distance observed between cluster 2 and 3 (1541) followed by 1 and 4 (Fig. 1). The minimum cluster distance was recorded between cluster 1 and 3 (494.61). The clusters showing maximum internal diversity can be utilized as a diverse pool to cross with the other clusters consisting maximum distance e.g. 2 and 3 . Similar studies were reported by Mortier et al., (2005) and Wang et al., (2008).

A dendrogram constructed based on the Ward's similarity index resulted in three major groups among which HUZM 152 found as a diverse inbred. Maximum clustering pattern is recorded at 600 unit distance which divides the rooted figure into two major clusters. Cluster 2 showed maximum number of inbreds indicates, the similarity in the genetic background of those inbreds. Similar studies were reported by Nikkhoy and Shiri (2017) and Iqbal et al., (2015).

Genetic variability and heritability and genetic advance parameters The results pertaining to phenotypic coefficient of variation (PCV), genotypic coefficient of variation (GCV), heritability (broad sense) and genetic advance expressed as percent of mean for all the characters under study are presented in Table 1. Phenotypic and genotypic coefficient of variation The ANOVA revealed considerable variations over the traits under study exhibiting a wide range of phenotypic as well as genotypic coefficient of variation. In general, the values of phenotypic coefficient of variance were higher than those of genotypic coefficient of variance. The relative magnitudes of the phenotypic as well as genotypic variances between the traits were compared based on the phenotypic and genotypic coefficient of variation. PCV was recorded highest for ASI (55.93) followed by yield per plant (33.00) and cob length (25.76). Low magnitude of PCV was exhibited by days to silking (3.77) followed by days to tasseling (3.8) and days to maturity (4.11). Rest other traits exhibited medium values of PCV. Similarly, GCV was also high for ASI (36.7) followed yield per plot (31.35) and cob diameter (14.3). Whereas, low magnitude of GCV was exhibited by grain yield per plant (1.74) followed by Per cent germination (2.64) and number of cobs per plot (2.73). The differences between the values of PCV and GCV were small for almost all the traits indicating less influence of environment in expression of these traits. However, the differences were comparatively greater in case of ASI grain weight per plant and number of cobs per plot. Heritability In the present study, heritability (broad sense) ranged from $35 \%$ to $95 \%$. The highest heritability was found in plant height and ear height $(95 \%)$ followed by days to maturity (93\%) and yield per plant $(89 \%)$. Lowest heritability was observed in effective tillers/plant (55\%) followed by harvest index (56\%). Other traits showed intermediate heritability Genetic advance Genetic advance as percent of mean (5\%) was realized highest for plant height (47.12) followed by biomass (32.29) and grain yield per plant (32.10). Lowest value was observed in percent germination followed by ASI (43) and days to maturity (55). The studies of variance among 20inbreds for 18 characters revealed that the genotypes differed significantly for all the characters which suggested that the materials selected for the studies might be of diverse origin. Several workers have reported the presence of 
variability in and amongst the genotypes of maize for different traits. These findings are in accordance with the findings of Gayatonde $e t$ al., (2017), Rajesh et al., (2013), Mahmood et al., (2004), Praveen Kumar et al., (2014). The early flowering and maturity was seen in three inbreds namely HUZM 152, HKI 193-1, HKI 1105 and HUZM 343 whereas inbreds HUZM-185 HUZM 329 and LM 10 exhibited late flowering and maturity suggesting that short duration genotypes can be used for evolving early maturity or short duration maize suitable for rainfed and zaid cropping areas. Late maturity in maize is a better ideotype character and inbreds showing better grain filling can be further utilized in various breeding purpose. Several workers Praveen Kumar et al., (2014) also reported positive as well as negative value for earliness in maize inbreds. The negative significant value for plant height is desirable because dwarf plant stature is essential to utilize for directed biomass accumulation in cobs, even believed to be lodging resistant.

The magnitude of genetic variability decides the effectiveness of selection. It is an established fact that greater the variability among the genotypes better is the chance for further improvement in the crop. But this variability can be utilized better if it is heritable. The heritable portion of the overall observed variation can be ascertained by studying the components of variation such as GCV, PCV, heritability and predicted genetic advance. In this study, the estimates of PCV were higher than their corresponding GCV for all the traits studied. These findings were similar to the findings of Kapoor and Batra (2017). The highest PCV and GCV were high recorded for ASI followed by cob length, grains yield per plot and grains yield per plant indicating that these traits were under the major influence of genetic control and less variable due to environmental factors. Therefore, such traits are important for further improvement. These findings are in close agreement with the researchers Ali et al., (2007) and Nagaraju (2012). The GCV provides a measure of comparison of variability and sometimes give some indication regarding validity of traits for selection. However, it does not provide clean picture of the extent of genetic gain to be expected from selection of phenotypic traits, unless heritable fraction of variation (heritability) is known (Burton, 1952). The difference between the values of PCV and GCV were small for almost all the traits except ASI, indicating less influence of environment in expression of these traits suggesting phenotypic differences may be considered as genetic difference among genotypes for selection.

Fig.1 Mahalnobi's Eucladian distance pattern

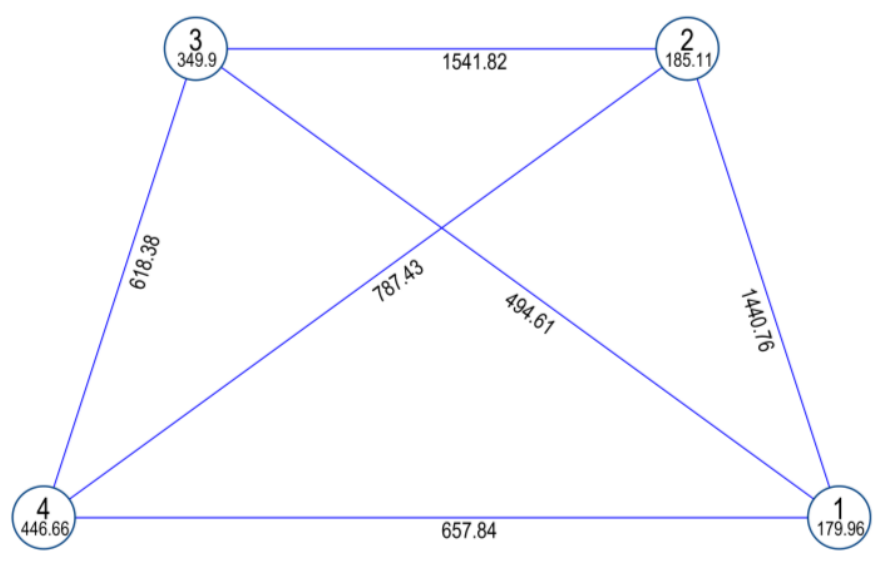


Table.1 Genetic variability parameters for various characters in 20 inbreds of maize

\begin{tabular}{|c|c|c|c|c|c|c|c|c|c|c|c|c|c|c|c|c|c|c|}
\hline & DT & DS & ASI & PH & EH & LA & PL & CL & CD & ROW & DM & TW & PG & TSS & MP & GP & NP & YP \\
\hline GCV & 3.541 & 3.447 & 36.753 & 8.584 & 14.301 & 12.904 & 14.895 & 25.588 & 14.873 & 9.825 & 3.961 & 14.751 & 2.638 & 10.072 & 6.317 & 1.742 & 2.731 & 31.359 \\
\hline PCV & 3.826 & 3.772 & 55.798 & 8.785 & 14.631 & 13.331 & 15.289 & 25.767 & 15.501 & 12.425 & 4.11 & 15.075 & 11.67 & 11.374 & 6.773 & 6.365 & 11.609 & 33.256 \\
\hline$h^{2}$ (Broad Sense) & 0.856 & 0.835 & 0.434 & 0.955 & 0.955 & 0.937 & 0.949 & 0.986 & 0.921 & 0.625 & 0.929 & 0.957 & 0.55 & 0.78 & 0.87 & 0.875 & 0.855 & 0.889 \\
\hline $\begin{array}{l}\text { Genetic } \\
\text { Advancement } \\
5 \%\end{array}$ & 7.393 & 7.292 & 1.463 & 20.882 & 15.13 & 0.991 & 8.671 & 7.506 & 1.18 & 2.219 & 11.801 & 6.143 & 0.21 & 0.746 & 0.572 & 0.091 & 0.227 & 1.881 \\
\hline $\begin{array}{l}\text { Gen.Adv as \% of } \\
\text { Mean } 5 \%\end{array}$ & 6.75 & 6.49 & 49.87 & 17.278 & 28.797 & 25.731 & 29.893 & 52.345 & 29.398 & 16.005 & 7.864 & 29.732 & 1.229 & 18.372 & 12.137 & 0.982 & 1.323 & 60.916 \\
\hline $\begin{array}{l}\text { Gen.Adv as \% of } \\
\text { Mean } 1 \%\end{array}$ & 8.651 & 8.317 & 63.91 & 22.142 & 36.905 & 32.975 & 38.31 & 67.083 & 37.675 & 20.511 & 10.078 & 38.103 & 1.574 & 23.545 & 15.554 & 1.258 & 1.696 & 78.067 \\
\hline General Mean & 109.525 & 112.358 & 2.933 & 120.863 & 52.541 & 3.853 & 29.007 & 14.339 & 4.015 & 13.867 & 150.067 & 20.661 & 17.1 & 4.06 & 4.717 & 9.228 & 17.15 & 3.088 \\
\hline $\begin{array}{l}\text { Exp Mean next } \\
\text { Generation }\end{array}$ & 116.918 & 119.65 & 4.396 & 141.746 & 67.671 & 4.844 & 37.678 & 21.845 & 5.195 & 16.086 & 161.868 & 26.804 & 17.31 & 4.806 & 5.289 & 9.319 & 17.377 & 4.969 \\
\hline
\end{tabular}

This also indicates that per-se performance of these traits should not be taken directly as the basis of selection other variability parameter for these traits such as heritability may also be taken into consideration. The relative magnitude of genotypic and phenotypic variances for the traits is the broad sense heritability and it is used as analytical role in selection procedures.

In the present investigation, high heritability was recorded for most of the characters except few traits. Heritability and genetic advance are important selection parameters. Heritability estimates along with genetic advance are normally more helpful in predicting the gain under selection than heritability estimates alone and indicates presence of additive variance or Additive $\mathrm{x}$ Additive type of interaction. It is not necessary that a character showing high heritability will also exhibit high genetic advance. The breeder should be cautious in making selection based on heritability as it indicates both additive and non-additive gene action. Thus, heritability values coupled with genetic advance would be more reliable and useful in formulating selection procedure as it indicates that most likely the heritability is due to additive gene effects. In the present set of materials, high heritability coupled with high genetic advance as percent was recorded for plant height, ear height and days to maturity, indicating effectiveness of selection for the improvement of these traits while high heritability coupled with low genetic advance as cob length, leaf area, cob length which is indicative of non-additive gene action. High heritability coupled with high genetic advance may be attributed to additive gene action (Khan, 1990). The high heritability is being exhibited due to favorable influence of environment rather than genotype and selection for such traits may not be rewarding. These results are in conformity with the findings of Ali et al., (2007) and Krishna et al., (2010).

\section{The major findings and implications are summarised as follows}

Analysis of variance for 20 maize inbreds with regards to yield and yield components revealed that the existence of significant differences among the genotypes studied for all the traits. There was a significant diversity found among the inbreds which was confirmed through $\mathrm{D}^{2}$ cluster analysis by obtaining two major clusters. These clusters can be further utilized for making diverse cross combinations and further heterotic pools which may help to opt best cross combination and heterotic for one or multiple traits. The Eucladian distance pattern analysis revealed favorable inter and intra-cluster distance, reveals scope for selecting diverse parents in breeding programs.

The maximum traits were recorded with close PCV and GCV values except ASI, percent germination and grain yield per plot. This shows the less influence of environment on 
the traits which are desirable to improve yield per-se. Four traits exhibited high heritability plus high genetic gain under selection reveals presence of additive variance and further scope for selection. Majority of the traits are recorded with high expected mean yield in the next generation, shows prediction is the better option if at all the objective is to select the inbreds for double or three way crosses.

\section{References}

Al-Badeiry NAH, Al-Saadi AH, Merza TK, Analysis of genetic diversity in maize (Zea mays L.) varieties using simple sequence repeat (SSR) Markers. Journal of Babylon University, 22(6):1768-1774. 2014

Anjali Kumari, Sweta Sinha, Kumari Rashmi, Mandal SS and Sanjay Sahay, Genetic diversity analysis in maize (Zea mays L.) using SSR markers,, Journal of Pharmacognosy and Phytochemistry SP1: 1116-1120, 2018.

Burton, G.W. Quantitative inheritance in grasses. Proc. 6th Int. Grasslands Cong. J., 1:227-283, 1952.

Farideh Nikkhoy and Mohammadreza, Shiri, Genetic Diversity Analysis of Maize Hybrids through Morphological Traits and Simple Sequence Repeat Markers, J. Plant Mol. Breed, 5(1): 49 - 60, 2017.

Javed Iqbal, Zabta Khan Shinwari and Malik Ashiq Rabbani, Maize (Zea mays L.) germplasm agro-morphological characterization based on descriptive, cluster and principal component analysis Pak. j. bot, 47(SI): 255-264, 2015.

Jian-cheng Wang, Jin $\mathrm{Hu}$, Xin-xian Huang, and Sheng-chun $\mathrm{Xu}$, Assessment of different genetic distances in constructing cotton core subset by genotypic values, J Zhejiang Univ Sci B. May; 9(5): 356-362, 2008.
Johnson, H.W.; Robinson, H.F. and Comstock, R.E. Estimates of genetic and environmental variability in soybean. Agron. J., 47: 274-318, 1955.

Krishna T, Kavita A and Pushpalata T, Genetic variability, heritability and genetic advance for quantitative traits in rice (Oryza sativa L.) accession, Agricultural and Biological Research, 26(1), 13-19, 2010.

Mahalanobis PC. On the generalised distance in statistics, Proceedings of the National Institute of Sciences of India, 2, 49-55, 1936.

Mortiera S, Robinb S, Lassalvy CP, Barilc A, Prediction of Euclidean distances with discrete and continuous outcomes BarHenJournal of Multivariate Analysis 97, $1799-1814,2006$.

Nagaraju, K, Studies on genetic variability for yield and yield attributing characters in maize (Zea mays L.), Thesis, ANGRAU, Hyderabad, 83-85, 2012.

Naushad Ali Turi, Salim Shah S, Sajid Ali, RahmanH, Tahir Ali and Muhammad Sajjad, Genetic variability for yield parameters in maize (Zea mays L.) genotypes, Journal of Agricultural and Biological Science, Vol. 2, 4-5, 2007.

Nechifor, Raluca Filimon, Lizica Szilagyi, Genetic variability, heritability and expected genetic advance as indices for yield and yield components selection in common bean (Phaseolus vulgaris L.) Scientific Papers. UASVM Bucharest, Series A 54: 332-337, 2011.

Ovung CY, Lal GM, and Rai PK, Studies on genetic diversity in rice (Oryza sativa L.), Journal of Agricultural Technology, 8(3), 1059-1065, 2012.

Praveen Kumar G, Narsimha Reddy V, Sudheer Kumar S and Venkateshwara Rao P, Genetic Variability, Heritability and Genetic Advance Studies in Newly Developed Maize Genotypes (Zea mays 
L.) Int. J. Pure App. Biosci. 2 (1): 272275, 2014.

Rahul Kapoor, Variability and character association studies in fodder maize (Zea mays L.) hybrids Forage Res., 43 (1): pp. 67-69, 2017.

Rajesh V, Sudeer Kumar S, Narsimha Reddy $\mathrm{V}$ and Siva Sanker A, Studies on genetic variability, heritability and genetic advance estimates in newly developed maize genotypes (Zea mays L.). International Journal of Applied Biology and Pharmaceutical Technology. 4(4): 242-245, 5, 2013.
Varsha Gayatonde, Prudhvi Raj Vennela, Mahadevu, Genetic Variability, Heritability and Other Quantitative Characters studies in Leading Varieties and Landraces of Rice (Oryza sativa L.), Environment \& Ecology, 35 (1B), 401-404, 2017.

Zahid Mahmood, Shahid Raiz Mailk, Raheel Akthar and Tariq Rafique, Heritability and genetic advance estimates from maize genotypes in Shishi Lusht a valley of Krakurm. International Journal of Agriculture and Biology, 2 (2): 253-257, 2004.

\section{How to cite this article:}

Varsha Gayatonde, J.P. Shahi, K. Srivastava and Prudhvi Raj Vennela. 2018. Assessment of Genetic Diversity and Variability of Maize (Zea mays L.) Inbreds. Int.J.Curr.Microbiol.App.Sci. 7(08): 1377-1383. doi: https://doi.org/10.20546/ijcmas.2018.708.157 